Dicle Tıp Dergisi / Dicle Med J (2019) 46 (4) : 633 - 640

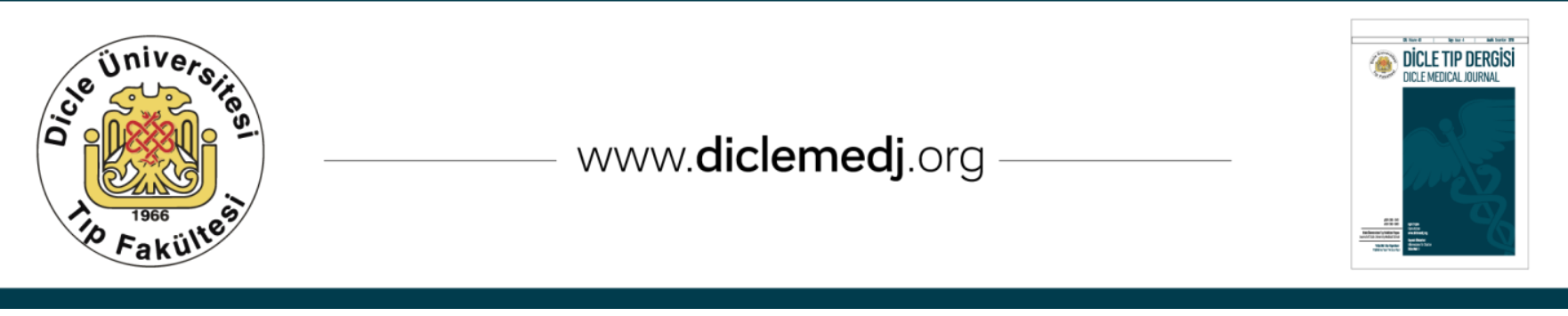

Özgün Araștırma / Original Article

\title{
Baş-Boyun BT Anjiyografi'de Otomatik Tüp Akımı Modülasyon Sisteminin Hasta Dozu ve Görüntü Kalitesi Üzerine Etkisi
}

\author{
Ayşegül Yurt ${ }^{1}$, Rukiye Çakır Haliloğlu² ${ }^{2}$ İsmail Özsoykal ${ }^{3}$, Gizem. Şişman ${ }^{4}$, Emel Ada ${ }^{5}$ \\ 1 Dokuz Eylül Üniversitesi, Sağlık Bilimleri Enstitüsü, Medikal Fizik Anabilim Dalı, İzmir, Türkiye Orcid: 0000-0001-9898-2329 \\ 2 Dokuz Eylül Üniversitesi, Sağlık Bilimleri Enstitüsü, Medikal Fizik Anabilim Dall, İzmir, Türkiye Orcid: 0000-0003-1465-2109 \\ 3 Dokuz Eylül Üniversitesi, Sağllk Bilimleri Enstitüsü, Medikal Fizik Anabilim Dal, İzmir, Türkiye Orcid: 0000-0002-5812-9347 \\ 4 Dokuz Eylül Üniversitesi, Sağlık Bilimleri Enstitüsü, Medikal Fizik Anabilim Dall, İzmir, Türkiye Orcid: 0000-0002-6134-9623 \\ 5 Dokuz Eylül Üniversitesi Tıp Fakültesi, Radyoloji Anabilim Dalı, İzmir, Türkiye Orcid: 0000-0002-0463-0945
}

Geliş: 20.03.2019; Revizyon: 30.10.2019; Kabul Tarihi: 04.11.2019

Öz

Giriş: Bilgisayarlı tomografi (BT) cihazları teknolojik gelişmeleri ile birlikte hastalıkların tanısında her geçen gün daha fazla kullanılmakta ve bunun sonucu olarak hasta dozlarında büyük bir artışa neden olmaktadır. Klinik olarak BT çekimleri çok yararlı olmasına rağmen, radyasyon dozu ve bunun meydana getirebileceği olası kanser riski geleceğin en büyük problemi olarak değerlendirilmektedir. Bu nedenle BT taramalarında, görüntü kalitesinden ödün vermeden görüntüleme parametrelerini kontrol ederek hasta dozlarının düşürülmesi temel ilke olmalıdır.

Amaç: Bu çalışmanın amacı, baş-boyun BT anjiyografi çekimlerinde otomatik tüp akım modülasyon (OTAM) sisteminin kullanılmasının hasta dozlarının azaltılması ve görüntü kalitesi üzerindeki etkilerini araștırmaktır.

Yöntemler: Serebrovasküler hastalık nedeniyle izlenen 23 hasta bu çalışmaya dahil edilmiştir. Sabit tüp akımı (mAs) kullanılarak yapılmış rutin baş boyun BT anjiyografi taramasının takibi için gelen hastaya tüm görüntüleme parametreleri sabit kalmak kaydıyla sadece otomatik tüp akımı modülasyonu tekniği kullanılarak tetkik gerçekleștirildi. Her iki yöntemle elde edilen veriler, hem hastaya verilen doz hem de görüntü kalitesi açısından değerlendirildi ve karşılaştırıldı.

Bulgular: Akım modülasyonu sistemi kullanıldığında etkin doz değerinde \%35'lik bir azalma gözlendi. Objektif değerlendirme için baş-boyun kısmında belirlenen 3 farklı anatomik bölgede sinyal-gürültü oranı (SNR) değerleri için beyin sapında \%49, omuz bölgesinde \%25, serebellumda ise \%42 lik bir azalma olduğu bulundu. Subjektif değerlendirmede ise akım modülasyon sistemi kullanılarak elde edilen görüntüler 2 radyolog tarafından incelendi ve 0-4 arasındaki puanlama sonucunda bu görüntülerin ortalama puanı 2,2 olarak bulundu. 
Sonuç: Baş-boyun anjiyo BT incelmelerinde otomatik akım modülasyonu ile radyasyon dozlarında belirgin azalma elde edilmiş, SNR nin azalmasına rağmen klinik açıdan tanısal kayıp olmadığı görülmüştür. Hasta dozlarının azaltılması ve tanısal açıdan dezavantaj oluşturmaması için uygun kriterlerde kullanılacak OTAM tekniğinin nöroanjiyo çekimlerinde rutin uygulamaya girmesi kesinlikle önerilmektedir.

Anahtar kelimeler: BT, Nöroanjiyo, hasta dozları, görüntü kalitesi, tanısal güvenilirlik

\title{
The Effect of Automatic Tube Current Modulation System on Patient Dose and Image Quality in Head-Neck CT Angiography
}

\begin{abstract}
Objective: Use of Computed Tomography (CT) in the diagnosis of diseases is increasing parallel to the technological advances in scanner designs, however, leading to a large increase in patient doses. Although the CT scans offer clinically useful information, the radiation dose and the potential risk of cancer is considered as the biggest problem for the future. For this reason, reducing the patient dose without leading to any degradation in the image quality must be the primary concern in CT scans.

Objectives: In this study, we aimed to investigate the effects of the use of automatic tube current modulation (ATCM) technique on patient dose and image quality in head-neck CT angiography scans.

Method: 23 patients have been included in the study who are being followed for their cerebrovascular diseases. Following the routine head and neck CT angiography protocol performed using constant tube current (mAs), next scan for the patients were carried out by using automatic tube current modulation technique, with all other exposure parameters held constant. Results obtained from two scanning methods were compared based on both dosimetric parameters and image quality.

Results: With the use of automatic tube current modulation technique, 35\% reduction was observed in the effective dose. For objective evaluation, signal-to-noise ratio (SNR) values of 3 different anatomical regions of the head and neck were reduced by $49 \%$ in the brain stem, $25 \%$ in the shoulder region, and $42 \%$ in the cerebellum, respectively. In the subjective evaluation, images have been rated by 2 radiologists according to a grading scale between $0-4$ and an average grade of 2.2 was obtained for the images acquired using automatic tube current modulation technique.

Conclusion: There was a significant decrease in radiation doses with the use of automatic tube current modulation in head and neck CT angiography. Despite decreases in SNR values, there was no handicap observed for achieving diagnostic purpose. According to these results, the routine use of automatic tube current modulation technique in CT neuroangiography exams is highly recommended.
\end{abstract}

Keywords: CT, neuroangiography, patient dose, image quality, diagnostic reliability.

\section{GíRIŞ}

Bilgisayarlı Tomografinin klinik uygulamaya girdiği günden beri, her geçen gün artan teknolojisiyle hastalıkların tanımlanmasında sıklıkla kullanılması hasta dozlarında artmaya neden olmaktadır ${ }^{1}$. Büyük tıp merkezlerinde yapılan son çalışmalar, radyoloji bölümlerinde gerçekleştirilen tüm uygulamaların sadece \%11'inin BT uygulamaları olduğunu, buna rağmen tanısal radyolojide hastaların aldığı etkin radyasyon dozlunun \%68'inin BT uygulamalarından kaynaklandığını göstermektedir ${ }^{2,3}$. BT uygulamalarında, dokularda absorbe edilen dozun 10-100 mGy gibi geniş bir aralıkta olması ve bu dozların alındığ ihtimalinin de arttığ dozlar, rotasyon başına volumetrik bilgisayarlı tomografi doz indeksi (CTDIvol) ve tarama alanı 
boyunca alınan doz (DLP) olarak ifade edilir. Işınlama parametrelerine bağlı olarak bir kesitteki dozu tanımlayan CTDIvol değeri, 10100 mGy arasında iken tüm tarama alanındaki toplam dozu tanımlayan DLP değeri ise 502000 mGy.cm aralığındadır ${ }^{4-6}$.

Bilgisayarlı tomografi uygulamalarına bağlı doz miktarlarındaki artış, yetişkin hastaların yanısıra özellikle büyüme çağında olan pediatrik hastaların sağlı̆̆ını daha fazla tehdit eden stokastik etki olma riskinin artmasıyla ilerleyen dönemlerde kansere yakalanma riskini de artırmaktadır. Bu bağlamda, bir tarafta doğru teşhis için kaliteli görüntü diğer bir tarafta hasta radyasyon dozu ve bu dozun hasta sağlı̆̆ değerlendirmeli ve buna göre bu tür uygulamalarda ALARA (as low as reasonably achievable) prensibi gözetilmelidir ${ }^{7}$.

BT'de hastanın radyasyon dozu, manuel seçilebilen tüp potansiyeli $(\mathrm{kVp})$, tüp akımı $(\mathrm{mA})$, rotasyon süresi ve "pitch" gibi parametrelerle kontrol edilir. Ancak, BT'de radyasyon dozunu azaltmak için otomatik ışınlama kontrolü sistemi farklı teknolojilerle tanımlanmıștır; otomatik ışınlama kontrolü ve otomatik tüp akımı modülasyonu (OTAM). OTAM tekniği hem açısal hem de boylamsal boyutlarda ayrı ayrı ya da birlikte uygulanabilmektedir. Açısal otomatik tüp akımı modülasyon sistemi, bir BT kesitini elde etmek için x ışını tüpünün 360 derecelik dönüşler boyunca gerçekleştirdiği lateral, AP-PA ve oblik ışınlamalar sırasında tüp akımını doku derinliğine ve yoğunluğuna göre ayarlayarak kullanır. Yaygın olarak kullanılan bir diğer teknik olan boylamsal OTAM tekniğinde ise, topogram adı verilen ve kesitsel BT görüntüleme öncesinde alınan iki boyutlu grafiden yola çıkılarak hastanın doku yoğunluğu ve kalınlığına bağlı radyasyon azaltım özellikleri hesaplanır. Bu bilgiler, BT taraması sırasında hastanın boylamsal ekseni boyunca tüp akımını modüle etmek için kullanılır. Farklı BT üreticilerinin farklı isimlerle piyasaya sunduğu bu iki teknik sayesinde tüp akımının, hastanın hiçbir bölgesinde ne artefakt yaratacak kadar düşük ne de hastaya gereğinden fazla doz verecek kadar yüksek olması sağlanır ${ }^{8-13}$. Şu ana kadar yapılmış olan çalışmalarda, otomatik tüp akımı modülasyon protokolleri uygulanarak yetişkinler için kranyum taramalarında \%50$\% 60$, abdomen için ise \%25-\%60 arasında doz azaltımları sağlanmış, bu şekilde elde edilen görüntülerin tanısal kalitesinin de yeterli derecede korunmuş olduğu belirtilmiştir 3,14,15. BT'de artan mA değeriyle radyasyon dozları artmakta, bununla birlikte görüntü kalitesi de artmaktadır. BT'de objektif görüntü kalitesi değerlendirmesi yapılırken gürültü indeksi (NI) ve sinyal/gürültü oranı (SNR) değerleri göz önüne alınır ${ }^{10,16-18}$.

Ülkemizde BT klinik uygulamalarında, hastaya yapılacak tetkiklerde çekim protokollerine ait bir standardizasyonun olmadığı görülmektedir. Bununla birlikte, kullanılacak parametrelerin seçimi ve hastaya o çekim sırasında ne kadar doz verileceği de tam olarak bilinmemektedir. $\mathrm{Bu}$ çalışma, standart baş-boyun BT anjiyo çekim protokolleri ile otomatik tüp akımı modülasyonu tekniğinin hasta dozları ve optimum görüntü kalitesi üzerindeki etkilerini belirlemeyi amaçlarken OTAM kullanımının rutin çekim protokollerine girmesinin önemini vurgulamaktadır.

\section{YÖNTEMLER}

$\mathrm{Bu}$ çalışma, üniversitemiz klinik olmayan çalışmalar etik kurulundan 2015/05-23 numaralı kararı ile etik onay almıştır. Retrospektif olarak gerçekleștirilen çalışmada, serebrovasküler hastalıklar nedeniyle başboyun BT anjiyo görüntülemesi yapılmak üzere Radyoloji bölümüne başvuran ve yaklaşık 6 aylık aralıklarla takibi yapılan 23 hasta değerlendirildi. Radyoloji bölümüne ilk olarak başvuran hastaya Philips Brilliance 16 Model, 64 kesitli BT cihazının sabit tüp akımlı rutin baş boyun BT anjiyo çekim protokolü uygulandı. 
Hasta takip için geldiğinde ise rutin çekim protokolündeki görüntüleme parametreleri değiştirilmeden, radyasyon doz azaltımını sağlayabilmek için cihaza ait boylamsal OTAM (Z-DOM) özelliği aktif hale getirildi ve oluşturulan bu yeni protokol uygulandı. $\mathrm{Bu}$ uygulamada rutin çekim protokolünde yer alan tüp voltajı $(\mathrm{kVp})$, kesit kalınlığı, "pitch" ve "inkrement" değerleri, taranan uzunluk, FOV (Field of view, Görüş alanı), tüp dönüș hızı, görüntü matris boyutları gibi değerler OTAM tekniğinde de sabit tutuldu (Tablo 1).

Tablo I: Baş-boyun BT anjiyo taramalarında rutin ve önerilen çekim protokollerinde kullanılan görüntüleme parametrelerini göstermektedir.

\begin{tabular}{lcc}
\hline $\begin{array}{l}\text { BT görüntüleme } \\
\text { parametreleri }\end{array}$ & $\begin{array}{c}\text { Rutin çekim } \\
\text { protokolü }\end{array}$ & $\begin{array}{c}\text { Önerilen çekim } \\
\text { protokolü }\end{array}$ \\
\hline $\begin{array}{l}\text { Etkin Tüp Akımı } \\
\text { (mAs/kesit) }\end{array}$ & 310 & Z-DOM \\
\hline Tüp Voltajı (kVp) & 120 & 120 \\
\hline $\begin{array}{l}\text { Kesit Kalınlığı } \\
\text { (mm) }\end{array}$ & 0.8 & 0.8 \\
\hline Pitch & 0.609 & 0.609 \\
\hline Inkrement & 0.4 & 0.4 \\
\hline $\begin{array}{l}\text { Tarama } \\
\text { Uzunluğu (mm) }\end{array}$ & 301.2 & 301.2 \\
\hline $\begin{array}{l}\text { Kolimasyon } \\
\text { (mm) }\end{array}$ & $64 \times 0.625$ & $64 \times 0.625$ \\
\hline FOV (mm) & 250 & 250 \\
\hline $\begin{array}{l}\text { Tüp Dönüş Hızı } \\
\text { (saniye/tur) }\end{array}$ & 0.5 & $512 \times 512$ \\
\hline Görüntü Matrisi & $512 \times 512$ & Standart (B) \\
\hline Görüntü Filtresi & Standart (B) & \\
\hline
\end{tabular}

\section{Hasta Dozimetrisi}

Dozimetrik karş̧laştırma için cihaz tarafından belirlenen, ışınlama parametrelerine bağlı olarak her kesitte alınan doz, CTDIvol (mGy) ve tüm tarama alanı boyunca toplam dozu belirlemede kullanılan DLP (mGy.cm) gibi parametreler göz önüne alındı. Çekimlere ait
DLP değerleri ve National Radiological Protection Board (NRPB) tarafından baş-boyun çekimleri için önerilen DLP başına etkin doz (E/DLP) katsayısı kullanılarak yaklaşı ortalama Etkin Doz (mSv) hesabı aşağıda gösterildiği gibi yapıldı:

$\mathrm{E}=\mathrm{EDLP} \times \mathrm{DLP}$

Burada E, mSv olarak çekim sırasında hastanın almış olduğu etkin radyasyon dozunu vermektedir. Baş-boyun BT çekimlerine ait EdLP (mSv/mGy.cm), DLP başına etkin doz katsayısı olup değeri $0.0031 \mathrm{mSv} / \mathrm{mGy} . \mathrm{cm}^{\prime} \mathrm{dir}^{3,19}$. BT uygulamaları sonucunda her iki çekim protokolüne ait ortalama hasta dozları hesaplandı ve karşılaştırıldı.

\section{Görüntü Kalitesi}

Çalışmanın dozimetrik karşılaştırmayı takip eden bu aşamasında, her iki çekim protokolüyle elde edilen görüntü kalitesinin objektif değerlendirmesinde NI ve SNR değerleri belirlenirken sübjektif değerlendirmede klinisyen gözüyle görüntü kalitesi tanımlanmıştır.

\section{Objektif Yöntem}

Her bir hastanın aynı pozisyondaki görüntüsünde aynı anatomik bölgeye ( beyin sapı, omuz, serebellum) yaklaşı $1 \mathrm{~cm}^{2}$ alana sahip dairesel ROI (region of interest) merkezleri çizildi (Şekil 1). ROI içerisinde kalan piksellere ait standart sapma değerinden gürültü indeksi (NI) ve Hounsfield Unit (HU) ile de sinyal değeri belirlendi. Her bir baş-boyun görüntülemesi için ard arda 3 kesitte ve aynı koordinatlarda çizilen ROI'un aracılığıyla NI'in ortalama değerleri belirlendi. Bununla birlikte ROI içindeki HU değeri ve ortalama NI değerlerinden her bir anatomik bölge için SNR değerleri hesapland $1^{8,10,14,17,18,20,21}$. 


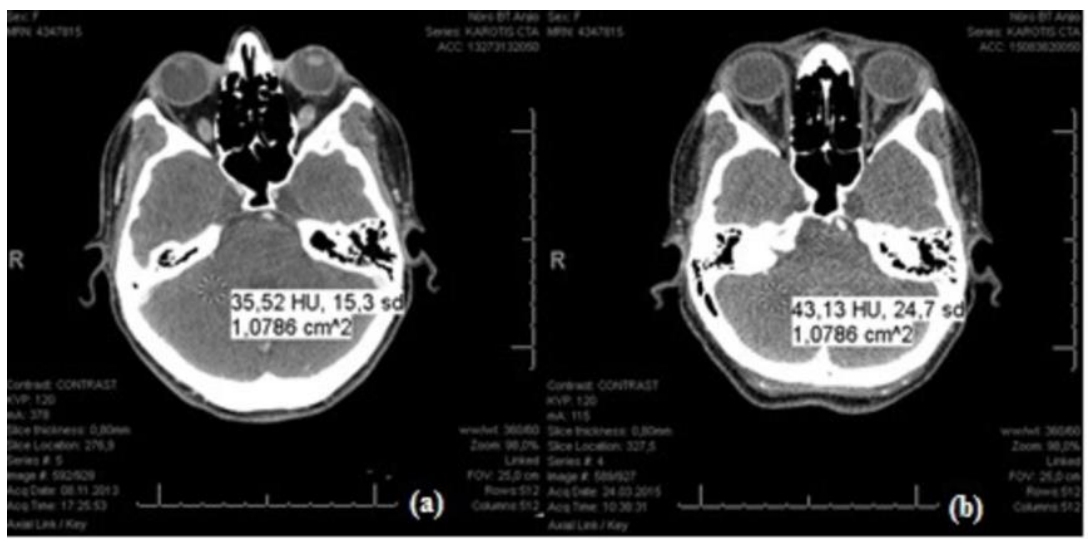

Şekil 1: a. Sabit akım b. Akım modülasyon sistemi ile elde edilen görüntüdeki BT görüntüsünde belirlenen ROI ve ölçüm değerleri

\section{Subjektif Yöntem}

Görüntü kalitesinin objektif olarak değerlendirilmesinin yanı sıra hastanemizdeki en az 15 yll deneyime sahip 2 radyoloji uzmanı, subjektif olarak her iki çekim protokolüne ait görüntülerde gürültü, artefakt ve anatomik yapıların görülebilirliğini değerlendirdi. Değerlendirme sırasında hasta ve çekim bilgileri görüntü üzerinde olmayacak şekilde planlama yapıldı. Bununla birlikte tüm görüntüler radyologlar tarafından kullanılan iş istasyonundaki aynı monitörde gerçekleştirildi. Subjektif görüntü kalitesi, 5'li değerlendirme ölçeğine (Tablo 2) göre gerçekleştirildi ${ }^{14,22}$. Bu ölçeğe göre 2 ve üzerinde notlandırılan görüntüler tanısal olarak başarılı kabul edildi ${ }^{23}$.

Tablo II: 5’li subjektif değerlendirme ölçeği

\begin{tabular}{|l|l|}
\hline Ölçek & Tanımlama \\
\hline 4 & $\begin{array}{l}\text { Gürültüye bağlı hiçbir sorun yaşanmamaktadır ve } \\
\text { görüntü kalitesi oldukça yüksektir }\end{array}$ \\
\hline 3 & $\begin{array}{l}\text { Görüntüde düşük seviyede gürültü gözlenmektedir } \\
\text { fakat diagnostik olarak güvenilir kalite korunmuştur }\end{array}$ \\
\hline 2 & $\begin{array}{l}\text { Görüntüde gözlenen gürültü orta seviyelerde fakat } \\
\text { başarılı bir diagnostik incelemeye elverişlidir }\end{array}$ \\
\hline 1 & $\begin{array}{l}\text { Görüntüde gözlenen yüksek seviyede gürültü güvenilir } \\
\text { bir diagnostik sonuca ulaşmaya engel olmaktadır }\end{array}$ \\
\hline 0 & $\begin{array}{l}\text { Gürültü herhangi bir tanısal değerlendirme yapılmasını } \\
\text { engelleyecek seviyededir. }\end{array}$ \\
\hline
\end{tabular}

\section{Verilerin Analizi}

Her iki inceleme grubuna ait CTDIvol, DLP, Etkin Doz, NI ve SNR verileri arasındaki karşılaştırmalarda veri setlerinin tümü normal dağılıma uymadığı için parametrik olmayan Mann-Whitney U testleri uygulandı.

\section{BULGULAR}

Çalışma sonucunda, hastalara göre sabit akım değerleri ve otomatik tüp akımı modülasyon sistemi kullanıldığında ne kadar değişiklik meydana geldiği Tablo 3'te gösterilmektedir. Her iki çekim protokolüne ait CTDIvol, DLP ve Etkin Doz değerleri arasında yapılan MannWhitney $U$ testlerinin tümünde anlamlı farklıllklar tespit edilmiştir $(\mathrm{p}<0.001)$. Uygulamalarda Z-DOM kullandığında $\mathrm{CTDI}_{\mathrm{vol}}$ değerlerinde \%38, DLP ve Etkin Doz değerlerinde ise \%35 oranında düşüşlerin sağlandığı görülmektedir.

Tablo III: Sabit akım ve Z-DOM protokolleri arasındaki dozimetrik farklılıklar

\begin{tabular}{|l|l|l|l|l|}
\hline Doz & $\begin{array}{l}\text { Sabit } \\
\text { Akım }\end{array}$ & Z-DOM & \% Azalma & p değeri \\
\hline CTDI $_{\text {vol }}(\mathrm{mGy})$ & 20.9 & 12.9 & 38 & $<0.001$ \\
\hline DLP (mGy.cm) & 799 & 522 & 35 & $<0.001$ \\
\hline Etkin Doz (mSv) & 2,48 & 1,62 & 35 & $<0.001$ \\
\hline
\end{tabular}


Görüntü kalitesi, sabit akım ile Z-DOM çekim protokolleri için hem objektif hem de sübjektif olarak değerlendirildi ve karşılaştırıldı. Serebellum, beyin sapı ve omuz olmak üzere farklı pozisyonlardaki BT görüntülerinden NI ve SNR değerleri hesaplandı (Tablo 4). İki farklı görüntüleme protokolüne ait NI ve SNR değerleri arasında yapılan Mann-Whitney $U$ testlerinin tümü anlamlı farklılıkla sonuçlandı $(\mathrm{p}<0.001)$.

Bununla birlikte Z-DOM tekniğini kullanarak elde edilen görüntülerde, Radyoloji uzmanlarının sübjektif değerlendirmesi sonucu görüntü kalitesine ait ortalama puan 2,2 olarak tespit edildi. Bu değer sabit tüp akımlı rutin protokol için 3.8 olarak kaydedildi (Tablo 5).

Tablo IV: Sabit akım ve Z-DOM protokolleri için NI ve SNR değerleri

\begin{tabular}{|l|c|c|c|c|c|c|}
\hline \multirow{2}{*}{$\begin{array}{l}\text { Anatomik } \\
\text { Bölgeler }\end{array}$} & \multicolumn{3}{|c|}{ NI } & \multicolumn{3}{c|}{ SNR } \\
\cline { 2 - 7 } & $\begin{array}{c}\text { Sabit } \\
\text { Akım }\end{array}$ & $\begin{array}{c}\text { Z- } \\
\text { DOM }\end{array}$ & $\begin{array}{c}\text { \% } \\
\text { Artış }\end{array}$ & $\begin{array}{c}\text { Sabit } \\
\text { Akım }\end{array}$ & $\begin{array}{c}\text { Z- } \\
\text { DOM }\end{array}$ & $\begin{array}{c}\text { \% } \\
\text { Azalma }\end{array}$ \\
\hline Serebellum & 10,91 & 16,60 & 52 & 4,04 & 2,33 & 42 \\
\hline Omuz & 28,27 & 35,53 & 26 & 2,10 & 1,57 & 25 \\
\hline Beyin sapı & 11,43 & 21,06 & 84 & 3,96 & 2,00 & 49 \\
\hline
\end{tabular}

Tablo V: Her iki protokol ile elde edilen görüntülerin subjektif değerlendirme puanları

\begin{tabular}{|l|l|l|}
\hline Subjektif Değerlendirme & Sabit Akım & Z-DOM \\
\hline $\mathrm{n}=23$ & 3.8 & 2.2 \\
\hline
\end{tabular}

\section{TARTIŞMA}

Çok kesitli bilgisayarlı tomografi cihazlarındaki hızlı gelişmeler nedeniyle hasta dozlarındaki artış ve bununla ilişkili olarak görüntü kalitesi için optimizasyon çalışması yapılması büyük önem taşımaktadır. BT'de hem radyasyon dozunu hem de görüntü kalitesini etkileyen görüntüleme parametreleri; $\mathrm{kVp}$ (tüp potansiyeli), mAs (tüp akımı-zaman), pitch, kesit kalınlığı, kesit sayısı ve tarama uzunluğudur. X ışınlarıyla görüntülemede, tüp akımı, hem görüntü kalitesi hem de radyasyon dozunun belirlenmesinde en önemli parametrelerden biridir. $\mathrm{Bu}$ amaçla yapılan baş-boyun, torax, abdomen ve pediatrik abdomen-pelvis çalışmalarında görüntü kalitesinden ödün vermeden tüp akımının azaltılması önerilmektedir. $\mathrm{Bu}$ da ancak tüp akımının vücut kütle endeksine (BMI) göre belirlenmesi anlamına gelmektedir. Bunun yanısıra yapılan son çalışmalarda, otomatik tüp akımı modülasyonu sisteminin, radyasyon dozu ve görüntü kalitesi üzerindeki etkileri incelenmiş ve kabul edilebilir bir görüntü kalitesiyle hasta dozlarında düşüş gözlenmiştir. Bununla birlikte hasta dozlarının düşürülmesi, görüntülemede direkt hedef organ olmamasına rağmen radyasyona duyarlı doku veya organların direkt radyasyona maruz kalmaları nedeniyle de büyük önem taşımaktadır ${ }^{15,24,25}$. Örneğin baş-boyun nöroanjiyo çekimleri sırasında yalnızca baş-boyun bölgesinin aldığı radyasyon dozu değil aynı zamanda taranan alanda yer alan lens ve tiroit gibi radyasyona duyarlı organların aldığı dozlar da göz ardı edilemeyecek kadar önemlidir.

6 aylık periyotlarla takip edilen baş boyun hastaları üzerinde gerçekleştirilen bu çalışma sonucunda Z-DOM kullanarak CTDI vol değerinde \%38, DLP ve toplam etkin doz değerinde ise \%35 oranında bir düşüşün sağlandığı görülmektedir (Tablo 3). Lee ve arkadaşlarının yaptığı bir çalışmada, sabit akım ve OTAM kullanım protokollerine göre radyasyon dozu ve gürültü indeksi karşılaştırılmıştır. $\mathrm{Bu}$ çalışmada, OTAM kullanımiyla hem CTDI $_{\text {vol }}$ hem de DLP değerinde \%45 oranında bir azalma olduğu raporlanmıştır. Aynı zamanda bu çalışılan grupta gürültü ile ilgili gözle görülür çok önemli değişiklikler kaydedilmemiştir ${ }^{20}$. Bu çalışmadaki doz azaltımının bizim çalışmamızdan daha fazla olmasının sebebi, açısal ve boylamsal olmak üzere her iki OTAM tekniğinin birlikte kullanılmış olmasıdır. S. 
Namasivayam ve arkadaşlarının boyun özelinde yaptıkları ve sadece boylamsal OTAM tekniğini uyguladıkları çalışmada ise farklı gürültü indeksi seçimine göre hasta dozundaki değişim gözlenmiştir. NI değerinin 8 olarak seçildiği durumda \%21, 10 olarak seçildiği durumda ise \%33'lük doz azaltımı kaydedilmiştir ${ }^{10}$. Beyin için yapılan başka bir çalışmada ise organ temelli otomatik akım modülasyonu tekniği kullanılmış ve göz için \%30,2'lik doz düşüşü sağladığı görülmüştür22. $\mathrm{Bu}$ bilgilere dayanarak, çalışma bulgularımızın literatürdeki bulgulara yüksek oranda paralellik gösterdiğini söyleyebiliriz.

Amerika'da BT tetkikleri ile ilgili dozimetrik veritabanı oluşturmaya yönelik yürütülen geniş çaplı bir çalışmada kontrastlı boyun tomografi incelemelerine ait radyasyon dozları kesit başına 20 mGy (CTDI ${ }_{v o l}$ olarak kaydedilmiştir ${ }^{26}$. Çalışmamızın bulgularına bakıldığında rutin protokolde 20.9 mGy olan bu değerin Z-DOM protokolü ile 12.9 mGy'e düştüğü görülmektedir. Dolayısıyla otomatik tüp akımı modülasyonunun ulusal bazlı kullanımının BT kaynaklı toplum dozlarında önemli bir azalma sağlayacağını söyleyebiliriz.

Görüntü kalitesinin objektif verilerine bakıldığında, NI değerlerindeki en büyük artış, en az radyasyon azaltımına karşıllk olarak tüp akımının da en fazla azaltıldığı beyin sapı bölgesinde gözlenmektedir. Radyasyon azaltım özelliği en yüksek olan omuz bölgesinde ise göreceli olarak yüksek tüp akımları uygulandığı için NI değerindeki azalma 3 bölge arasında en düşük seviyededir. SNR değerleri de NI değerlerine paralel olarak seyretmiştir. Objektif olarak görüntü kalitesinin değerlendirildiği NI değerindeki artış ve bunun sonucunda SNR değerlerindeki azalmanın literatürle uyumlu olduğu görülmüştür ${ }^{10,20}$. Subjektif değerlendirme sonucunda ise Z-DOM tekniğiyle tanısal yönden kaliteli görüntülerin elde edildiği sonucuna varılmıștır.
Sonuç olarak, BT baş-boyun incelemelerinde, ZDOM tekniğiyle gürültü indeksinin artmasına rağmen tanısal değere sahip kaliteli görüntü elde edilirken hastanın aldığı radyasyon dozu azaltılmıștır.

Çıkar Çatışması Beyanı: Yazarlar çıkar çatışması olmadığını bildirmişlerdir.

Finansal Destek: Bu çalışma her hangi bir fon tarafından desteklenmemiştir.

Declaration of Conflicting Interests: The authors declare that they have no conflict of interest.

Financial Disclosure: No financial support was received.

\section{KAYNAKLAR}

1. AAPM Report 96. The Measurement, Reporting and management of radiation dose in CT. USA. 2008; 1-34.

2. Frush D, Denham CR, Goske MJ, et al. Radiation protection and dose monitoring in medical imaging: a journey from awareness, through accountability, ability and action but where will we arrive? J Patient Saf. 2012; 8: 1-11.

3. Dougeni E, Faulkner K, Panayiotakis G. A review of patient dose and optimisation methods in adult and paediatric CT scanning. Eur J Radiol. 2012; 81: 665-83.

4. Wiest PW, Locken JA, Heintz PH, et al. CT scanning: a major source of radiation exposure. Semin Ultrasound CT MR. 2002; 23: 402-10.

5. Feng ST, Law MWM, Huang B, et al. Radiation dose and cancer risk from pediatric CT examinations on 64-slice CT: a phantom study. Eur J Radiol. 2010; 76: 19-23.

6. Rogers LF. Radiation Exposure in CT: Why So High? AJR. 2001; 277.

7. Parker MS, Kelleher NM, Hoots JA, et al. Absorbed radiation dose of the female breast during diagnostic multidetector chest CT and dose reduction with a tungsten-antimony composite breast shield: preliminary results. Clin Radiol. 2008; 63: 278-88.

8. Spampinato S, Gueli AM, Milone P, et al. Dosimetric changes with computed tomography automatic tubecurrent modulation techniques. Radiol Phys Technol. 2018; 11: 184-91. 
9. Greffier J, Larbi A, Macri F, et al. Effect of patient size, anatomical location and modulation strength on dose delivered and image-quality on CT examination. Radiat Prot Dosimetry. 2017; 177: 373-81.

10. Namasivayam S, Kalra MK, Pottala KM, et al. Optimization of Z-axis automatic exposure control for multidetector row CT evaluation of neck and comparison with fixed tube current technique for image quality and radiation dose. Am J Neuroradiol. 2006; 27: 2221-5.

11. Lee $\mathrm{CH}, \mathrm{Goo} \mathrm{JM}, \mathrm{Ye} \mathrm{HJ}$, et al. Radiation dose modulation techniques in the multidetector CT era: from basics to practice. Radiographics. 2008; 28: 14519.

12. Yurt A. Bilgisayarlı Tomografide Radyasyon Dozu ve Doz Azaltıcı Yöntemler. Turkiye Klinikleri J Radiol. 2014; 7: 33-9.

13. Lee $\mathrm{CH}$, Goo JM, Lee $\mathrm{HJ}$, et al. Radiation dose modulation techniques in the multidetector CT era: from basics to practice. RadioGraphics. 2008; 1451-59.

14. Zhao YX, Zuo ZW, Hong-Na Suo MM, et al. CT pulmonary angiography using automatic tube current modulation combination with different noise index with iterative reconstruction algorithm in different body mass index: image quality and radiation dose. Acad Radiol. 2016; 23: 1513-20.

15. Fu W, Tian X, Sturgeon GM, et al. CT breast dose reduction with the use of breast positioning and organbased tube current modulation. Med Phys. 2017; 44: 665-78.

16. Kim S, Yoshizumi TT, Frush DP, et al. Dosimetric characterisation of bismuth shields in CT: measurements and Monte Carlo simulations. Radiat Prot Dosimetry. 2009; 133: 105-10.

17. Sookpeng S, Martin CJ, Gentle DJ, et al. Relationships between patient size, dose and image noise under automatic tube current modulation systems. J Radiol Prot. 2014; 34: 103-23.
18. Chen JH, Jin EH, He W, et al. Combining automatic tube current modulation with adaptive statistical iterative reconstruction for low-dose chest CT screening. PLoS One. 2014; 9: e92414.

19. Shrimpton PC, Hillier MC, Meeson S, et al. Doses from computed tomography (CT) examinations in the UK 2011 Review. Public Health England. 2014; 1-87.

20. Lee EJ, Lee SK, Agid R, et al. Comparison of image quality and radiation dose between fixed tube current and combined automatic tube current modulation in craniocervical CT angiography. Am J Neuroradiol. 2009; 30: 1754-9.

21. Dehairs M, Bosmans H, Desmet W, et al. Evaluation of automatic dose rate control for flat panel imaging using a spatial frequency domain figure of merit. Phys Med Biol. 2017; 62: 6610-30.

22. Wang J, Duan X, Christner J, et al. Bismuth shielding, organ-based tube current modulation, and global reduction of tube current for dose reduction to the eye at head CT . Radiology. 2012; 262: 191-8.

23. Mulkens TH, Bellinck P, Baeyaert M, et al. Use of an automatic exposure control mechanism for dose optimization in multi-detector row CT examinations: clinical evaluation. Radiology. 2005; 237: 213-23.

24. Curtis JR . Computed Tomography Shielding Methods: A Literatüre Review. Radiol Technol. 2010; 81: 428-36.

25. Brenner DJ and Elliston CD. Estimation radiation risks potentially associated with full-body CT screening. Radiology. 2004; 232: 735-8.

26. Kanal KM, Butler PF, Sengupta D, et al. U.S. Diagnostic Reference Levels and Achievable Doses for 10 Adult CT Examinations. Vol. 284, Radiology. 2017. p. 120-33. 